
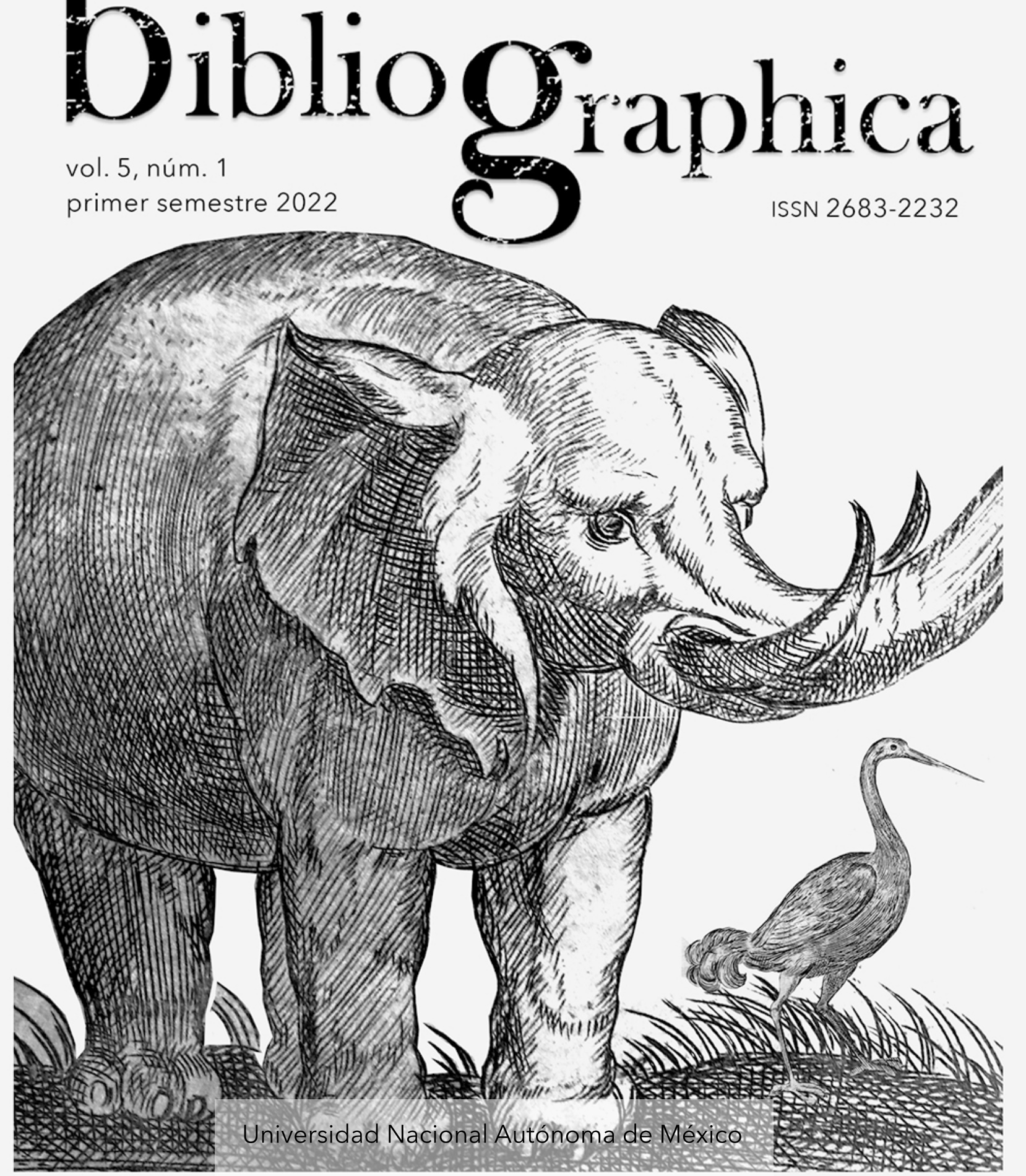


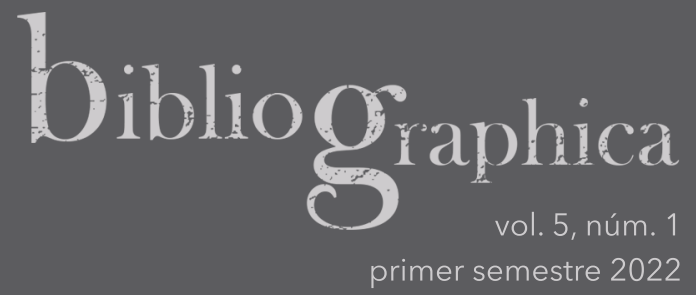

\section{Traducción y adaptación de Practica in arte chirurgica copiosa, de Juan de Vigo, en los tratados breves de fray Agustín Farfán}

Translation and Adaptation of Practica in arte chirurgica copiosa, of Juan de Vigo, in the Short Treatises of Friar Agustín Farfán

\section{Marcos Gortés Guadarrama}

Universidad Veracruzana,

Instituto de Investigaciones Lingüístico-Literarias,

Veracruz. México

marccortes@uv.mx

https://orcid.org/0000-0002-0363-7539

Recepción: 11.10.2021 / Aceptación: 19.12.2021

DOI: https://doi.org/10.22201/iib.2594178xe.2022.1.281 
Resumen

Palabras clave

Abstract

Keywords
Este artículo estudia la relevancia de un hecho en el que, hasta el momento, no había reparado la historia de la medicina, la historia del libro ni la filología: el Tratado breve de cirugía (1579) y el Tratado breve de medicina (1592) traducen y adaptan parte del contenido anatómico y quirúrgico que escribió Juan de Vigo en su Practica in arte chirurgica copiosa (1514). La propuesta es que este hecho no resta originalidad a los dos tratados del médico agustino fray Agustín Farfán, señalando que el tratamiento de la obra del médico del papa Julio II -además de otros factores más allá del texto- influyó en el desequilibrio editorial existente entre los dos tratados. Se concluye con una posible justificación del porqué el último tratado (1592) sería reeditado en 1610, ya bajo el beneficio de la Orden de San Agustín; determinamos una respuesta que atiende a cuestiones políticas, propias de una orden religiosa mendicante que fue de las primeras en convertirse en una institución criolla.

Fray Agustín Farfán; Tratado breve de cirugía; Tratado breve de medicina; Juan de Vigo; Practica in arte chirurgica copiosa; medicina novohispana.

This article studies the importance of an event which, up to now, has been ignored by fields such as Medical History, Book History, and Philology: in Tratado breve de cirugía (1579) and in Tratado breve de medicina (1592), there is a part of adaptation and translation from the anatomical and surgical information that the Italian surgeon Giovanni da Vigo wrote in his Practica in arte chirurgica copiosa (1514). It is posited that this fact did not interfere with the originality of the treatises written by the Augustinian doctor Agustín Farfán. Furthermore, it is noted that the treatment of the work of Pope Julius II's physician -besides other factors beyond the text- had an influence on the difference in the number of editions between the two books. Finally, this text provides a possible answer to why the last treatise (1592) was republished in 1610 under the profit of the Augustinian Order, which responded to political matters proper to a religious mendicant order that became one of the first criollo institutions.

Friar Agustín Farfán; Tratado breve de cirugía; Tratado breve de medicina; Juan de Vigo; Practica in arte chirurgica copiosa; medicine in New Spain. 


\section{Introducción}

En el Fondo Reservado de la Biblioteca Nacional de México (BNM) yace uno de los ejemplares originales del Tractado breve de chirurgía y del conocimiento y cura de algunas enfermedades que en esta tierra más comúnmente suelen aver, ${ }^{1}$ impreso en México por Antonio Ricardo, obra médica de fray Agustín Farfán (1532-1604). La historia de la medicina y la historia de la cultura de los últimos años no han ignorado la figura de este doctor agustino y las ideas asentadas en sus dos escritos conocidos: este primero, de 1579, y el último, de 1592, impreso por Pedro Ocharte. Por supuesto, las intenciones y alcances de los trabajos historiográficos que le aluden son variados, ${ }^{2}$ algunos más logrados que otros, pero recientemente la mayoría de ellos se enfocan en este último tratado, ${ }^{3}$ que vio la luz en México hace 430 años. Sin lugar a dudas, fue su libro más célebre. La historiografía agustiniana ${ }^{4}$ llegó a decir que formaba parte de los bienes de todo español que se encontrase lejos de los centros urbanos y necesitase de una cura casera ante un malestar ligero o una terrible enfermedad. Si bien tales afirmacio-

${ }^{1}$ En adelante Tratado breve de cirugía. Existen dos portadas del texto, el ejemplar de la BNM la ha perdido y un folio escrito a mano destaca su contenido "chirúrgico" (véase Imagen 3); hay otro ejemplar en la Huntington Library que aún la conserva. Mi más sincero agradecimiento y reconocimiento a Yarí Pérez Marín por facilitarme una copia de esta portada. Como se aprecia (véase Imagen 4), su título deja en claro que antes del aspecto "chirúrgico", se destaca el "anathómico": Tractado breve de anathomía y chirurgía, y de algunas enfermedades, que más comúnmente suelen haver en esta Nueva España. Los dos títulos han oscilado, entre los historiadores de la medicina que refieren este libro. Desde mi punto de vista los dos son correctos, pues antes de la intervención del cuerpo, mediante la cirugía, la anatomía lo denomina y le otorga una proporción. Además, las siguientes páginas prueban que el influjo del tratado de 1579 proviene de un libro que lleva por título Practica in arte chirurgica, por tanto, la oscilación entre los títulos es válida. ${ }^{2}$ Sirvan sólo tres referencias para ilustrar los extremos temporales de este interés que, hasta el momento, nunca ha decaído entre los historiadores de la medicina, desde la segunda mitad del siglo XX. Por supuesto, don Joaquín García Icazbalceta dedica un apartado a los textos médicos en su Bibliografía Mexicana del siglo XVI, ed. de Agustín Millares Carlo (México: FCE, 1981) [1a. ed. 1954]. Además de éste, uno de los primeros trabajos que toma en cuenta a Farfán es el de Saul Jarcho, "Medicine in the Sixteenth-Century. New Spain as Illustrate by the Writings of Bravo, Farfán and Vargas Machuca", Bulletin of the History of Medicine, núm. 31 (1957): 425-444, y uno de los últimos es el de Yarí Pérez Marín, Marvels of Medicine (Liverpool: University Press, 2020).

${ }^{3}$ Existe ya una reciente edición, selección y notas de este libro, antecedido por un provocador estudio: Fray Agustín Farfán, Tratado breve de medicina y de todas las enfermedades, ed. de Marcos Cortés Guadarrama (Madrid: Iberoamericana / Vervuert, 2020).

${ }^{4}$ Esteban García, Crónica de la Provincia Agustiniana del Santísimo nombre de Jesús de México, Libro quinto (Madrid: Imprenta G. López Hornos, 1918), 26. 
nes le hacen el juego a una hagiografía del autor, lo cierto es que este libro será el único de tema médico que alcance una reedición en los 300 años de Nueva España, en 1610, en la imprenta de Gerónimo Balli, ubicada en la Ciudad de México. Así pues, la popularidad que se dice que tuvo, si bien no debe caer en la exageración agustiniana, no fue del todo extremada, pues sí que se le ha encontrado en algunas de las bibliotecas novohispanas de médicos del siglo XVIII, como la del doctor Joseph Thomás Araujo y García del Valle (1712-1776). ${ }^{6}$

Es decir que, principalmente a partir de esta obra y desde ahí hacia todo el conjunto de obras farfanianas, los historiadores han celebrado una intención médica rica en ideas, creencias y costumbres híbridas propias de la medicina novohispana, desde la segunda mitad del siglo XVI hasta las primeras décadas del XVII. Sin embargo, dentro de este hecho, quizá sí que se ha pasado por alto una cuestión que atañe y preocupa, particularmente a la historia del libro y a la filología. Y es que, en este contexto, cabría preguntarse: ¿qué es lo que hizo que su Tratado breve de cirugía, de 1579, no gozase del éxito editorial de su segunda obra, Tratado breve de medicina, de 1592 y 1610 ? ¿Qué características arroparon su primera obra, condenándola a una suerte editorial inferior?

En las presentes páginas desarrollo una posible respuesta a estas preguntas, la cual radica -a mi parecer y entre otras cuestiones más allá del texto- ${ }^{7}$ en

\footnotetext{
${ }^{5}$ Este hecho sin tomar en cuenta las dos ediciones novohispanas del Tesoro de medicinas del venerable Gregorio López. Aquí la reedición se involucra, directamente, con el apoyo e impulso de un fallido proceso de beatificación y no por el contenido médico que prodigaba esta obra. Véase Marcos Cortés Guadarrama, "Cefalea en mujeres novohispanas (1613-1727): invenciones fallidas de la medicina y de la hagiografía en la Vida del siervo de Dios Gregorio López", en La sombra de Thánatos: enfermedad, muerte y viudedad en los siglos XVI y XVII, de próxima aparición.

${ }^{6}$ Se trata de la edición de 1610, con el primer folio faltante. María Luisa Rodríguez-Sala y Verónica Ramírez Ortega, Los médicos en la Nueva España y sus redes sociales. Etapa preilustrada (1730-1779) (México: UNAM, 2016), 395.

${ }^{7}$ Es un hecho que el primer tratado de Farfán nació bajo cierto influjo de la terrible peste "cocolistle" de 1576, mientras que el tratado de 1592 surgió en tiempos más benignos. Asimismo, la experiencia -que tanto valora el autor en su Tratado breve de medicina (1592)-, incluso cuando puede verse como un tópico narrativo de la literatura médica de la época, es fundamental para su cambio de visión en su segundo tratado, donde valora más la atención de males comunes con productos que fácilmente se encontraban en los tianguis o por intermediación de los indígenas, que el aspecto quirúrgico y anatómico propiamente dirigido no al lector de a pie, sino a otros colegas del arte de la medicina, tales como cirujanos romancistas y barberos. Véase Cortés Guadarrama, "Estudio introductorio" en Farfán, Tratado breve de medicina y de todas las enfermedades (Madrid: Iberoamericana / Vervuet, 2020),19-172.
} 
el tratamiento de la fuente primordial que, en cierto sentido, originó la poética médica farfaniana que, si bien sustentada en la brevedad, realmente proviene de la copiosidad.

Para explicar esta respuesta tengo que remontarme 65 años antes de la publicación del Tratado breve de cirugía (primera obra de nuestro médico agustino, como se ha dicho). Así pues, en 1514 se publica en latín la Practica in arte chirurgica copiosa del médico genovés Juan (loannes, Giovanni) de Vigo (14601525). Además de abordar temas propios de la cirugía, anatomía, remedios, tratamientos para diversas enfermedades, etc., la obra ha pasado a la historia -entre otras cuestiones- por ser si no el más eficaz, sí el más célebre y conocido documento de la literatura médica que registra, por primera vez, la atención de las heridas provocadas por arma de fuego. ${ }^{8}$

Tres años después aparecerá su Practica in arte chirurgica compendiosa, que resume de manera más manejable la mayoría de los postulados de su primera publicación. A grandes rasgos, la historia de la medicina suele reconocer que en la obra de Vigo yace un cuadro muy logrado de lo que era el arte de la cirugía bajomedieval y de su tiempo. De este modo dará inicio una de las trayectorias editoriales más exitosas en el arte de la medicina durante el XVI-y dos siglos posteriores-, con varias impresiones en latín y traducciones al italiano, inglés, francés y, por supuesto, castellano.

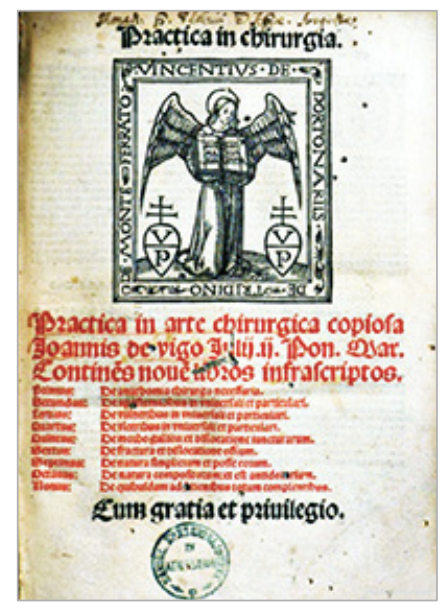
Imagen 1. Portada de Practica in arte chirurgica copiosa (1519), de Juan de Vigo. Biblioteca Histórica de la Universidad Complutense de Madrid.

\footnotetext{
${ }^{8}$ Andrea A. Conti, "The Anatomical and Historical Background of Surgery: Major Surgical Achievements during the Middle Ages and the Renaissance", Italian Journal of Anatomy and Embryology, núm. 124 (2019): 212-215.
} 
La tradición de traducciones castellanas se inaugura en 1537 con la realizada en Valencia por el doctor Miguel Juan Pascual, ${ }^{9}$ a la cual le siguen cinco reediciones que llegarán hasta el siglo XVIII. ${ }^{10}$ Para el médico de Castellón es importante asumir una traducción en la que sus comentarios y anotaciones al margen del cuerpo del texto sean fundamentales para complementar y corregir lo postulado por Vigo. Este hecho debe invitarnos a pensar que -más que una intención reprobatoria o examinadora, opuesta a la tradición recogida y representada por Vigo- la traducción y notas de Pascual son esfuerzos por movilizar una obra y el conocimiento que recoge y transmite. En este sentido, la divulgación y circulación de la obra del médico del papa Julio Il para el orbe hispánico no terminará ahí, todo lo contario.

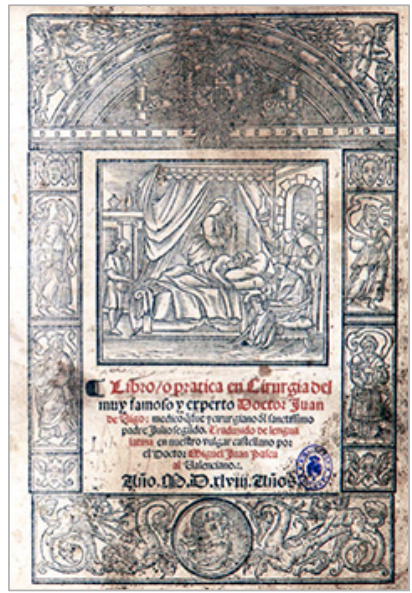

Imagen 2. Libro o práctica en cirurgía (1548), de Juan de Vigo. Trad. de Miguel Juan Pascual. Biblioteca Nacional de España.

Como es sabido, las nociones de una medicina bajomedieval galenista arabizada, aunadas a las del humanismo renacentista, realizarán un viaje trasatlántico mediante el asentamiento de médicos, cirujanos, boticarios, instituciones preocupadas por la salud y el comercio de libros médicos durante los 300

\footnotetext{
${ }^{9}$ Con el título: Libro o práctica en cirurgía del muy famoso y experto doctor Juan de Vigo: médico que fue y cirurgiano del sanctíssimo padre Julio segundo. Traducido de lengua latina en nuestro vulgar castellano.

${ }^{10}$ En la imprenta madrileña de Ángel Pasqual Rubio saldrá la edición de 1717, aclarándose en portada: "Nuevamente impressa, y de las faltas que tenía la otra impresión, en esta van corregidas".
} 
años de los virreinatos americanos. ${ }^{11}$ Este tipo de medicina -a grandes rasgos, escolástica y medievalizante- ${ }^{12}$ será la que seguirán los médicos y cirujanos romancistas en Nueva España durante la segunda mitad del siglo XVI y hasta buena parte del XVIII. Así pues, no es de extrañar que Juan de Vigo sea llamado "príncipe de los cirujanos" por uno de los cirujanos novohispanos más importantes de su tiempo, Alonso López de Hinojosos (ca. 1535-1597). En su Suma y recopilación de cirugía algunos temas no encontrarían fundamento de no ser por lo propuesto por Vigo - principalmente a partir del tratado III-, en lo que incumbe a los "apostemas", la "oftalmia", el "pólipo", la "esquinencia", etc. ${ }^{13}$ Incluso recomienda un remedio que lleva el nombre de la autoridad que lo inspira: "polvo de Juan de Vigo" y un "emplasto o ceroto tan estimado de Juan de Vigo". ${ }^{14}$ Muchas de estas cuestiones se repetirán en su segunda obra: Suma y recopilación de cirugía (México: Imprenta de Pedro Balli, 1595).

Si López de Hinojosos leyó a Vigo en una traducción castellana o en el original, en latín -o, menos probable, en alguna otra lengua romance-, es un planteamiento cuyas especulaciones serán tratadas líneas abajo. De momento, interesa destacar lo que se manifiesta con claridad en los tratados de Hinojosos:

${ }^{11}$ Mariana Labarca, "Los libros de medicina en el Chile del siglo XVIII: tipologías, propietarios y dinámicas de circulación", Anuario Colombiano de Historia Social y de la Cultura 47, núm. 2 (2020): 345-371.

12 Un ejemplo de ello es la conceptualización y empleo del cuerno de unicornio en la medicina novohispana durante casi trescientos años. En Marcos Cortés Guadarrama, "El cuerno de unicornio en la Nueva España: conocimiento boticario y prescripción de médicos", Revista Historia de América, núm. 161 (2021): 275-306.

${ }^{13}$ Los primeros dos tratados de la obra de Hinojosos están fuertemente influenciados por el cirujano más famoso de la Baja Edad Media, el francés Guy de Chauliac, castellanizado Guido de Cauliaco. Y por momentos hace dialogar las ideas de los dos autores más citados en su libro: Cauliaco y Vigo. Por ejemplo: "[las] hinchazones como dice Guido de sangre, que son las mismas que Juan de Vigo pone de cólera, a lo cual llamó formica, escachilos, estiómenos, fuego pérsico o pruna. Y para que no parezca que desacuerdan estos dos tan famosos doctores en decir uno que esta enfermedad es de sangre y el otro que es de cólera, ambos dicen verdad y se entiende de esta manera como se entiende de los flemones cuando sobreviene con la sangre cólera, flema o melancolía y así uno toma del cuero, otro toma de la carne, más o menos según la malicia del humor", Alonso López de Hinojosos, Suma y recopilación de cirugía. Con un arte para sangrar muy útil y provechosa, ed. de Germán Somolinos d'Ardois, Roberto Olivera, Samuel Fastlicht y Alfredo López Austin (México: Academia Nacional de Medicina, 1977), 118. [1a ed. México: Antonio Ricardo, 1578].

${ }^{14}$ Ibid., 111-120, 130, 132, 136, 151. Sobre el emplasto de Vigo, véase José María Rumbo Prieto et al., "Revisión histórica sobre el uso en heridas del emplasto confortativo de Vigo", Enfermería Dermatológica, año 11, núm. 31 (2017): 36-42. 
él sí cita y reconoce la influencia de Vigo en su trabajo. Quizá esto se debe a la conocida subordinación del cirujano hacia el médico en la época. No obstante, más allá de estos hechos y otras incertidumbres a las que insta la obra de Hinojosos -imposibles de abarcar aquí-, el propósito de las siguientes páginas es centrarme en un aspecto en el cual no se había reparado hasta que fue anunciado en otro trabajo: ${ }^{15}$ las partes quirúrgica y anatómica que recrea Farfán, primero en su Tratado breve de cirugía y luego en su Tratado breve de medicina, están tomadas directamente de la obra de Vigo sin que el agustino le dé algún crédito al médico genovés.

Es decir, es el propio Farfán, quien traduce ciertos postulados de Vigo y los presenta como suyos, además de copiar -específicamente en su libro de 1579- parte de la misma organización con la que el genovés realizó su obra. Por supuesto, el concepto de plagio tal y como hoy en día se asume está fuera de la conceptualización de la creación de la literatura médica del siglo XVI -y también de otras literaturas-, pues en esa época toda copia era un acto de creación original y las obras de Farfán lo son en un amplio sentido. Por tanto, en el presente ensayo se intentará aclarar ese concepto de originalidad en las obras del agustino y en qué sentido la traducción y adaptación que hace de Practica in arte chirurgica copiosa de Vigo incide tanto en su propia aportación a la literatura médica novohispana como en la descompensada popularidad de sus dos tratados.

\section{Tratado breve de cirugía (1579)}

No hay que avanzar mucho en la lectura del primer tratado de medicina del agustino para encontrar los conceptos de Vigo; antes de los mismos, hay una velada advertencia en el proemio al "Lector": Farfán no sólo dice que es un médico docto en su materia, con "veintisiete años" de experiencia, sino que se ha propuesto con este libro sacar "lo mejor de los autores, así griegos como bárbaros, y de los modernos, lo mejor que en sus escriptos dexaron de la chirurgía". ${ }^{16}$

\footnotetext{
${ }^{15}$ Cortés Guadarrama, "Estudio introductorio", 157-165.

${ }^{16}$ Agustín Farfán, Tratado breve de cirugía y del conocimiento y cura de algunas enfermedades que en esta tierra más comúnmente suelen haber (México: Antonio Ricardo, 1579), f. 1. Habría que reconocer que la intención de Farfán es un tópico que se manifiesta en la tradición de la literatura médica, incluso en el mismo "Proemio" de Vigo: "Aunque no poca copia de libros antiguos y modernos de lengua arábica, latina y griega en cirurgía tratantes casi por todo el mundo [...] rogado por algunos amigos y en alguna manera forçado para que compusiesse algo en la sciencia de la cirurgía no pude dexar de sacar a
} 


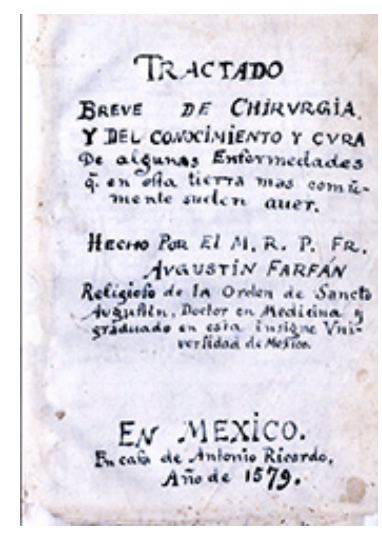

Imagen 3. Tratado breve de cirugía

(1579), de fray Agustín Farfán.

Biblioteca Nacional de México (BNM).

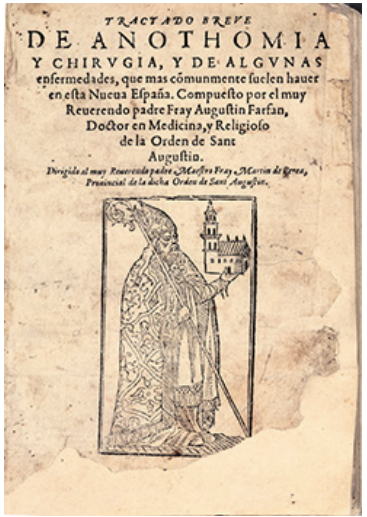

Imagen 4. Tratado breve de anathomía y cirugía (1579), de fray Agustín Farfán. Huntington Library.

Y este esfuerzo es para "todos" los que necesitasen de ello por alguna razón -sobre todo para los ibéricos y criollos que estuviesen lejos de los centros urbanos, donde no había fácil acceso a boticas y otros servicios propios de la ciudad-. Por supuesto, ese concepto señalado por el autor, y que refiere a una totalidad, en realidad está restringido a un selecto número de individuos que pudiesen acceder a la materialidad de la cultura escrita en lengua romance, concretamente en castellano, sin que ello conllevara el conocimiento de los autores "modernos" y sus respectivas obras, menos aún en Nueva España.

Esa es precisamente la misión de Farfán, al menos la que él mismo quiere señalar: aproximar al lector interesado hacia una tradición del pensamiento médico y, en específico, hacia uno de los trabajos que juzgaba "de los modernos". Uno de entre ellos, y el más notable en su prosa, es Juan de Vigo, autoridad que no tiene ningún reparo en seguir al pie de la letra, tomándose sólo pequeñas libertades en su traducción:

luz alguna obrezilla en el arte de cirurgía", Juan de Vigo, Libro o prática [sic] en cirurgía del muy famoso y experto doctor Juan de Vigo: médico que fue y cirurgiano del sanctíssimo padre Julio segundo ([S. I: s. i.], 1548), f. I. 


\begin{tabular}{|l|l|l|}
\multicolumn{1}{|c}{$\begin{array}{c}\text { Practica in arte chirurgica } \\
\text { copiosa (1519). }\end{array}$} & \multicolumn{1}{c|}{$\begin{array}{c}\text { Libro o práctica } \\
\text { Juan de Vigo }\end{array}$} & \multicolumn{1}{c|}{$\begin{array}{c}\text { Tratado breve de cirugía } \\
\text { de Miguel Juan Pascual }\end{array}$} \\
\hline $\begin{array}{l}\text { Anatomia aut est scientia } \\
\text { recta qua singulatim membris } \\
\text { humani corpis incisione } \\
\text { dividunt. Et prepterea de ab } \\
\text { ana grece quod est rectuz: } \\
\text { e tomos quod est divisio inde } \\
\text { recta quasi membro et divisio } \\
\text { (ff. IIIr-IIlv). }\end{array}$ & $\begin{array}{l}\text { Anathomía es sciencia recta } \\
\text { con la qual los miembros } \\
\text { del cuerpo humano } \\
\text { singularmente con incisión } \\
\text { son divididos: y por tanto } \\
\text { es dicha de ana griego/ } \\
\text { que es recta y thomos/ que } \\
\text { es división: y day quasi recta } \\
\text { división de los miembros } \\
\text { (f. Illr). }\end{array}$ & $\begin{array}{l}\text { Anathomía pues, es una } \\
\text { sciencia recta y derecha, } \\
\text { con la qual dividimos, cortando } \\
\text { los miembros del cuerpo } \\
\text { humano, con singularidad, } \\
\text { como la etimología del } \\
\text { vocablo lo declara, el qual } \\
\text { viene deste nombre griego. } \\
\text { Ana, que es recta, y thomos, } \\
\text { que es división (f. 3r). }\end{array}$ \\
\hline
\end{tabular}

Desde tiempos muy remotos, la difusión del arte de la medicina se ha fundamentado en la traducción. ${ }^{17}$ Sin pretender remontarme a la importante labor traductora de la medicina árabe a inicios del siglo IX, con figuras como Mesué, ${ }^{18}$ me gustaría recordar que ya en la Baja Edad Media castellana el concepto "enterpretador"19 estaba asociado al arte de la medicina. Así se comprueba en la traducción del Breviarium ab urbe condita de Eutropio (1377-1399), en el que se declara: "Enta Pergamo de Asia aquesti fue mucho claro enterpretador de Ypocras et clarecio encara en Athenas et en Alexandria, en los quales lugares mucho prouecho en philosophia et en medecina. Et estan i muchos liuros medicinales". ${ }^{20}$ Es decir, para prolongar lo señalado en torno a la llamada Herencia medieval de México, ${ }^{21}$ aquí Farfán dilata en su quehacer como médico novohispano una acción cuya conceptualización no sólo se restringía a la mera traducción, sino cuya heurística comprendía también otras acciones propias de la creación de la literatura médica de la temprana modernidad, como la selección,

\footnotetext{
${ }_{17}$ Para el tema de la traducción de literatura médica véase VV. AA., Traducción y transmisión doctrinal de la medicina grecolatina desde la Antigüedad hasta el Mundo Moderno, ed. de María Teresa Santamaría Hernández (Cuenca: Ediciones de la Universidad Castilla-La Mancha, 2016).

${ }^{18}$ Ramón Madrigal Lomba, El Renacimiento. Época y medicina (Xalapa: Universidad Veracruzana, 2015), 249-252.

${ }^{19}$ El documento más antiguo donde se recoge el término "enterpretador" es en los Milagros de Nuestra Señora (1246-1252), de Gonzalo de Berceo. Consultamos la ed. de Fernando Baños (Madrid: Crítica, 1997).

${ }^{20}$ Real Academia Española, CORDE, s. v. "enterpretador", f. 54v.

${ }^{21}$ Luis Weckmann, La herencia medieval de México, 2 vols. (México: El Colegio de México, 1984).
} 
el comentario, la exposición y explicación de lo que, a juicio del autor, era lo que se debía sacar de un autor "moderno" que le ha precedido en sus intenciones de escribir, en este caso, sobre lo que es la anatomía, para así proceder con la intervención del cuerpo mediante la cirugía.

Tras la definición citada, el agustino pasa a otra información y no prosigue con la traducción de Vigo, quien, inmediatamente después de lo referido, cita a una de las autoridades en cirugía más célebres del periodo bajomedieval, Guido de Cauliaco (Guy de Chauliac, 1298-1368). Siguiendo el curso de los hechos comentados hasta ahora, surgen por lo menos dos preguntas: ¿por qué sacar a la luz un libro de cirugía en Nueva España?, y ¿por qué dentro de la tradición de las obras y famosos autores de cirugía que le antecedieron -uno de los cuales (Cauliaco) es referido por el propio Vigo- Farfán se decantó, precisamente, por el genovés?

La primera de estas preguntas quizá se responda al pensar que un año antes de la publicación del Tratado breve de cirugía, Farfán fue uno de los tres revisores del mencionado libro del cirujano Alonso López de Hinojosos. Su texto encabeza el de las otras conocidas y respetadas autoridades de la medicina novohispana: el doctor Francisco Bravo, como se sabe, autor del Opera medicinalia (México: Pedro Ocharte, 1570), y el primer doctor en ostentar la cátedra de medicina en la Real y Pontificia Universidad de México, Juan de la Fuente, cuya figura ha inspirado trabajos muy recientes. ${ }^{22}$

\section{Dice Farfán:}

He visto este libro intitulado Suma y recopilación de cirugía compuesto por el Maestre Alonso López, cirujano, dedicado al Ilustrísimo y Reverendísimo señor Arzobispo de esta ciudad; y por su Señoría a mí cometido para que lo viese y diese mi parecer para imprimirse, el cual libro por estar yo justamente ocupado, a mi ruego e intercesión vio y enmendó el doctor Bravo con mucha deliberación y lo ha aprobado y parece que también lo ha visto el doctor de la Fuente Protomédico nombrado por esta ciudad y se conforma con él en su parecer. Por lo cual por haberlo yo visto muy particularmente, es mi parecer que se pueda dar licencia para imprimirlo, y digo que lo leí todo sin faltar nada y enmendé en él algunas cosas que por el que lo trasladó con descuido no advirtió, y que no estaban convenientes. Y que es libro necesario y muy útil

${ }^{22}$ Gerardo Martínez Hernández, "Más allá de la primera cátedra de medicina en el Nuevo Mundo: tiempo, vida y obra de Juan de la Fuente", Asclepio 72, núm. 2 (2020): 314. 
para la tierra donde estamos y conozco al autor de él desde hace muchos años ha, y sé que ha sido hombre curioso, deseoso en saber y aprovecharse en todo, y así lo ha mostrado en esta su obra, la cual toda ha experimentado con buen entendimiento, juicio y celo cristiano. Y por verdad la firmé. Fecho en México, a dos de febrero de 1578 años. ${ }^{23}$

Hay algunos fallos en la obra del cirujano que corrigió Farfán, atribuidos a quien "lo trasladó con descuido no advirtió, y que no estaban convenientes". ¿A qué se refiere Farfán con esta declaración? ¿Alude al propio autor, quien, por ser un cirujano romancista, no supo trasladar correctamente el mensaje de un original latino a causa de sus carencias en el idioma? ¿O más bien quien "lo trasladó" se trata de otra persona -que no es el autor-, siendo el verdadero responsable de lo que, a juicio de Farfán, merecía la corrección? Si nos decantamos por esta última variante, ¿quiere decir, posiblemente, que Hinojosos escribía en lengua romance tal y como la hablaba, generando confusión en el lector y, en consecuencia, requirió de alguien -ajeno al arte de la medicinaque lo trasladara de manera correcta? Las dos variantes expuestas bien podían ser sorteadas por un médico como Agustín Farfán que, debido a su educación universitaria, primero en Sevilla y luego en Alcalá de Henares, tenía el poder de extraer todo conocimiento directamente del latín, gracias a su manejo del idioma.

Además, por su evidente dominio de la escritura, no dependía de terceras personas para materializar sus ideas en beneficio de "estas tierras" alejadas del corazón de la Corona española. Así pues, podría considerarse que éste fue uno de los motivos que lo llevaron a escribir su propia obra de cirugía con tan sólo un año de diferencia de la publicación del libro de Hinojosos. Un libro cuyo propósito sería superar a la autoridad medieval de Guy de Chauliac, quien, por cierto, curaba de un modo que no era del agrado de Farfán; ${ }^{24}$ un libro -repito- que se enfocaría exclusivamente en lo que para el autor sería lo más "moderno", nuevo y de su gusto en los ramos de anatomía y cirugía, respondiendo así a las demandas de su propio tiempo.

Especulaciones aparte, lo que sí se evidencia es que, si bien es positiva la valorización y el quehacer de un cirujano como Hinojosos ("hombre curioso, deseoso en saber y aprovecharse en todo"), la primera intención que lo mueve a escribir como autoridad del arte de la medicina era dejar en claro lo que no

${ }^{23}$ López de Hinojosos, Suma y recopilación de cirugía, 72.

24 "Para curar estos panerizos pone el Guido muchas cosas, las quales a mí no me agradan, ni satisfacen", Farfán, Tratado breve de cirugía, f. 107v. 
debían hacer cirujanos mediocres, quienes quizá se veían en la temeraria circunstancia de trabajar sin la compañía del médico:

la cantidad de cada sangría sea de quatro onças, el número de quántas han de ser las sangrías, dexo a lo que le pareciere al docto médico, y aunque el cirujano lo puede hazer, hasse de entender, con necesidad, no aviendo médico en el pueblo, que si lo ay, peccará mortalmente, si no lo haze llamar, para que él corriga los acidentes todos de la enfermedad, mas ay dolor, que ningún cirujano he visto que haga esto, ni se precie de ello, mas antes, sangra, purga, y ordena otros muchos remedios, sin tener conocimiento de ellos, ni cómo, quándo, y a quién los ha de aplicar, y poner. Y viendo yo esta miseria, y que con ellos no ha de aver remedio, he tomado este trabajo, y es. Ponerles aquí toda enfermedad, y curación, todo lo que deven hazer, sin que les falte cosa alguna, como lo verán. Y si alguno me reprehendiere, diciendo que con esto lo harán mejor, le respondo, que esto pretendo, y es, que lo hagan mejor, teniendo esta luz, y porque el cirujano que estuviere sin médico se govierne y riga por este tractado, y así no offenderá a Dios ni al próximo, que curare. ${ }^{25}$

Es decir, la intención de Farfán de escribir su primer tratado también responde a una jerarquía que él encabeza como médico, validado por el ámbito universitario y otras instituciones relacionadas con la salud, como el Protomedicato de Nueva España. Por otra parte, el esfuerzo de sacar a la luz su propio libro de cirugía también estaría relacionado con las circunstancias históricas que aún se dejarían sentir en 1579. En efecto, la pestilencia del "cocolistle", ${ }^{26}$ que en 1576 tuvo una de sus oleadas más brutales y requirió que cirujanos y médicos pusiesen su mejor esfuerzo para tratar de salvar a los súbditos indígenas, quienes la resintieron con mayor gravedad por encima de otras comunidades, tales como los peninsulares o criollos.

\footnotetext{
${ }^{25}$ lbid., f. 52v.

${ }^{26}$ Se ha señalado que ninguno de los apartados del tratado alude directamente al "cocolistle", sin embargo: "cuenta con un excelente apartado sobre tabardete y sangrados nasales. Fueron consideradas las enfermedades anteriores debido a que la última fue el síntoma más mencionado en códices y crónicas para el cocoliztli de 1545, y el tabardete por ser uno de los nombres con los que fue conocida la enfermedad hasta el siglo XIX, cuando se hizo la distinción entre tabardete y tabardillo, refiriendo la primera a fiebre tifoidea y la segunda a tifo exantemático", Sandra Elena Guevara Flores, "La construcción sociocultural del cocoliztli en la epidemia de 1545 a 1548 en la Nueva España" (tesis de doctorado, Universitat Autònoma de Barcelona, 2017), 161.
} 
Además, cuatro años antes del terrible año del "cocolistle", Farfán ve divididas sus ocupaciones como religioso agustino -orden a la que ingresó en 1568y como médico, atendiendo en el Hospital de Jesús -junto a De la Fuente- a los recién llegados jesuitas, que enfermaban de vómito. ${ }^{27}$ Sin lugar a dudas, su libro de 1579 también responde a estas dos vocaciones suyas, la religiosa, tal y como se comprueba en el remedio "para que puedan confessar los que están en lo último de su vida", ${ }^{28}$ y a la propiamente médica, según pudimos leer en la advertencia a los cirujanos. En otras palabras, Farfán fue instando por tres flancos para realizar este libro: dar a conocer, en su propia traducción, la auctoritas moderna en cirugía (Juan de Vigo); escribir sobre cirugía y anatomía como médico de formación universitaria, lo que a los cirujanos romancistas les estaba imposibilitado o limitado, y responder a las terribles circunstancias que giraron en torno a la peste de "cocolistle", que le tocó vivir en carne propia.

Para tratar de profundizar en una respuesta a la segunda pregunta planteada, es decir, el porqué basar su propio trabajo en el libro de Vigo y no en otros cirujanos, antes habría que precisar algunas diferencias. Así pues, si bien Farfán traduce con pocas libertades en algunos segmentos de su trabajo:

\begin{tabular}{|l|l|l|}
\multicolumn{1}{c}{$\begin{array}{c}\text { Practica in arte chirurgica } \\
\text { copiosa (1519). } \\
\text { Juan de Vigo }\end{array}$} & \multicolumn{1}{c|}{$\begin{array}{c}\text { Libro o práctica } \\
\text { en cirurgía (1548). }\end{array}$} & \multicolumn{1}{c|}{$\begin{array}{c}\text { Tratado breve } \\
\text { de cirugía (1579). } \\
\text { Agustín Farfán }\end{array}$} \\
\hline $\begin{array}{l}\text { Visso in doctrina precedenti } \\
\text { de membris cotentis videndum } \\
\text { est deinde de membris conti- } \\
\begin{array}{l}\text { nentibus in ventre. Et primo } \\
\text { de siphac dicemdum est (f. Xr). }\end{array}\end{array}$ & $\begin{array}{l}\text { Visto en toda la doctrina } \\
\text { pasada de los miembros con- } \\
\text { tenidos, avemos de ver de los } \\
\text { miembros continenetes en el } \\
\text { vientre: y primero del Sifac } \\
\text { se ha de decir (f. XIIIr). }\end{array}$ & $\begin{array}{l}\text { Aviendo tratado en la doctrina } \\
\text { passada de los miembros con- } \\
\text { tenidos, es bien que digamos } \\
\text { ahora de los continentes en } \\
\text { el vientre, y el primero que se } \\
\text { offrece es el Siphac o Peritonio } \\
\text { (f. 21r). }\end{array}$ \\
\hline
\end{tabular}

En otros casos selecciona, resume, adapta o sencillamente omite lo que considera fundamental para el desarrollo de su propia obra. Así, por ejemplo, en la primera parte, dedicada a la anatomía, no sigue letra por letra a Vigo, pero sí se amolda, en lo general, a los contenidos asentados por el genovés. Asimis-

${ }^{27}$ Germán Somolinos d'Ardois, Capítulos de Historia médica mexicana. Relación alfabética de los profesionistas médicos, o en conexión con la medicina, que practicaron en territorio mexicano (1521-1618), t. III (México: Sociedad Mexicana de Historia y Filosofía de la Medicina, [1978]), 223.

${ }^{28}$ Farfán, Tratado breve de cirugía, ff. 265v-266r. 
mo, hay coincidencia nada más al terminar este capítulo. De tal modo que si en la Practica in arte chirurgica copiosa el libro segundo está dedicado a las apostemas, así ocurre en el Tratado breve de cirugía de Farfán. Sin embargo, el número de capítulos de su obra no se corresponde con el libro que le sirve de guía al agustino. En este aspecto, y en la organización de los materiales y, por supuesto, en su tratamiento, es en donde se observa la verdadera originalidad de la obra del médico novohispano, al margen de los préstamos tomados de Vigo:

\begin{tabular}{|c|c|c|}
\hline $\begin{array}{c}\text { Practica in arte } \\
\text { chirurgica copiosa (1519). } \\
\text { Juan de Vigo }\end{array}$ & $\begin{array}{l}\text { Libro o práctica } \\
\text { en cirurgía (1548). Trad. } \\
\text { de Miguel Juan Pascual }\end{array}$ & $\begin{array}{c}\text { Tratado breve } \\
\text { de cirugía (1579). } \\
\text { Agustín Farfán }\end{array}$ \\
\hline $\begin{array}{l}\text { Primus: De anathomia chirurgo } \\
\text { necessaria. } \\
\text { Secundus: De apostemaribus } \\
\text { in universali et particular. } \\
\text { Tertius: De vulneribus in } \\
\text { universali et particular. } \\
\text { Quartus: De ulceribus } \\
\text { in universali et particulari. } \\
\text { Quintus: De morbo gallico } \\
\text { et dislocatione iuncturarum. } \\
\text { Sextus: De fractura et disloca- } \\
\text { tione ossium. } \\
\text { Septimus: De natura simpli- } \\
\text { cium et posse eorum. } \\
\text { Octavus: De natura composi- } \\
\text { torum et est antidotarium. } \\
\text { Nonus: De quibusdam additio- } \\
\text { nibus totum complentibus. }\end{array}$ & $\begin{array}{l}\text { Libro primero de la nothomía } \\
\text { [sic]. } \\
\text { Libro segundo de los } \\
\text { apostemas. } \\
\text { Libro tercero de las llagas. } \\
\text { Libro quarto de las úlceras } \\
\text { en universal. } \\
\text { Libro quinto del mal francés. } \\
\text { Libro sexto del quebrantamien- } \\
\text { to de los huessos. } \\
\text { Libro séptimo de la natura } \\
\text { de los simples. } \\
\text { Libro octavo de antidotario } \\
\text { Libro noveno de las addiciones }\end{array}$ & $\begin{array}{l}\text { Primera parte de la anathomía. } \\
\text { Segunda parte de los } \\
\text { apostemas. } \\
\text { Tercera parte de la cura } \\
\text { particular de todos } \\
\text { los tumores desde la cabeza } \\
\text { hasta los pies. }{ }^{29} \\
\text { Quarta parte de las llagas } \\
\text { frescas. }{ }^{30} \\
\text { Quinta parte de las úlceras. } \\
\text { Sexta parte de la flaqueza } \\
\text { del estómago. }{ }^{31}\end{array}$ \\
\hline
\end{tabular}

También habría que detallar que mientras Vigo escribió un capítulo aparte para el mal francés, Farfán lo incorpora en la quinta parte "de las úlceras". Así pues, a partir del folio 217 ("capítulo décimo primo"), el encabezado en cada página del lado recto dice "de las bubas", enfermedad que, a diferencia de Vigo, Farfán recomendará curar con un elemento propio de la tradición de la materia

\footnotetext{
${ }^{29}$ En el recto de cada página se vuelve a repetir el encabezado: "de los apostemas", tal y como aparece en la segunda parte.

${ }^{30}$ El título está tomado del encabezado que aparece en cada página de la cuarta parte.

${ }^{31}$ Esta parte inicia en el f. 223, con el siguiente encabezado: "Tractado sexto y último, de algunas enfermedades que comúnmente suelen haver en esta tierra".
} 
americana, el guayacán, árbol en el que también confiaba Monardes en $1574,{ }^{32}$ pero del cual desconfiaba y se desdecía el doctor Pedro Arias de Benavides en su tratado de $1567 .^{33}$

Por otro lado, la sexta y última parte del tratado de Farfán también dividirá sus contenidos, pero en lugar de dos apartados, como el capítulo anterior, serán seis: a partir del folio 227 tratará "del Tabardete"; desde el f. 236, "del dolor de costado"; f. 241, "de las cámaras de sangre"; f. 249, "de la esquilencia"; f. 253, "de la cólica pasión" y, finalmente, f. 257, "de diversos remedios". La subdivisión de estos apartados en el encabezado del folio recto tiene un fin práctico, para que el interesado lector pudiese llegar a ellos sin necesidad de revisar el índice, sino sólo con una rápida hojeada del libro. Y el éxito y originalidad de este sexto y último apartado será el que inspirará la poética de su segundo tratado, de 1592, tal y como se abordará más adelante. Pero antes: ¿qué es lo que Farfán pudo haber visto en Vigo para guiar su trabajo?

Practica in arte chirurgica copiosa era uno de los libros más destacados para la cirugía del siglo XVI. El autor quizá fue conocido por Farfán durante su paso por las aulas de Alcalá de Henares, ${ }^{34}$ universidad con una cátedra de medicina más volcada hacia el humanismo renacentista y a autores modernos, a diferencia de Salamanca, que estaba más de cara con la tradición medievalizante del arte médico en la Península lbérica. ${ }^{35}$ Asimismo, aún contamos con el registro de un inventario y almoneda de 1578 en el cual se dice que, a la muerte del salamantino Juan Gutiérrez de Grado, asentado en Nueva España, donde tenía una casa y tienda donde vivía, cerca de la Plaza Mayor de México, poseía hierros de cirujano, un estuche y unas tijeras de barbero junto a cuatro libros: el

\footnotetext{
32 Nicolás Monardes, Primera y segunda y tercera partes de la historia medicinal de las cosas que se traen de nuestras Indias Occidentales, que sirven en medicina (Sevilla: Alonso Escrivano, 1574).

${ }_{33}$ Pedro Arias de Benavides, Secretos de chirurgia (Valladolid: Francisco Fernández de Córdoba, 1567). Para el planteamiento de Arias de Benavides y su entender de la materia médica americana, véase Marcos Cortés Guadarrama, "Lactancia y lactantes novohispanos: prefiguración de un mal más allá del cuerpo. Un caso del eclecticismo literario en el arte médico de la Nueva España", Melisendra, núm. 2 (2020): 68-86.

34 Juan de Vigo era un referente quirúrgico en la Universidad de Alcalá de Henares, junto con otros cirujanos destacados de Francia e Italia, tales como: "Ambrosio Paré, Bartolomé Maggio, Dino de Florencia, Antonio Musa Brassavola, Gianbattista Theodosio, Valleriolla, Nicolao Massa, Andrés Mattiolli y Gianbattista Montagnana", en Antonino Vidal Ortega, "Los inicios de la ciencia moderna en el Caribe neogranadino: Pedro López de León, teoría y práctica en la cirugía de la Cartagena del siglo XVII", Asclepio 72, núm. 2 (2020): 316.

${ }_{35}$ Martínez Hernández, "Más allá de la primera cátedra...", 314.
} 
Abecedario espiritual de Francisco de Osuna y un Libro de la verdad de Pedro de Medina, además de un Dioscórides y el otro Juannes de Vigo. ${ }^{36}$

Durante el siglo XVII, concretamente en 1640, los libreros sevillanos Antonio de Toro y Juan López Román enviaron a Nueva España "2 Çirugia de Bigo". ${ }^{37}$ En un inventario de 1764, el comerciante de libros novohispano don Phelipe Perez del Campo y Gonzalez poseía los siguientes libros de medicina: Madama Fouquet, Obras medico-chirurgicas; Felipe Borbón, Medicina y cirugía doméstica, y Giovanni de Vigo, Libro o pratica en Cirugia. ${ }^{38}$ Finalmente, a Juan de Vigo se le menciona en 1894, en la tesis de Luis Carreño que presentó con el título de "Algunas consideraciones acerca de la Pomada Mercurial doble", para obtener título de Farmacéutico-Químico en Puebla. ${ }^{39}$

Es decir que durante los 300 años de Nueva España y en el primer siglo de su independencia, el conocimiento de la obra de Juan de Vigo nunca decayó y se le tenía como referencia y autoridad médica de importancia sobresaliente. De hecho, el "emplasto confortivo de Juan de Vigo" estará presente en la farmacia del orbe hispánico hasta la prohibición de la elaboración de fármacos con plomo, en el siglo XX.40 Algo de esta contundencia debió haber intuido Farfán en la obra de Vigo, además de que, como médico del papa Julio II, poseía todas las credenciales de aceptabilidad para el orbe católico contrarreformista.

La posición de nuestro médico agustino en la divulgación de la Practica in arte chirurgica copiosa a través de su Tratado breve de cirugía debe pensarse como una reescritura normativa y ortodoxa: desde los distintos recursos retóricos empleados en su obra, nunca falta a la normatividad que concede la auctoritas que inspira la idea aportada al arte médico novohispano. La intención sirve y cumple con la institucionalidad médica y religiosa que regulaba la acción y ex-

\footnotetext{
${ }^{36}$ Archivo General de Indias (AGI), Contratación, 226, n. 1, r. 1, ff. 29v, 31v-32v. Mi más sincero agradecimiento para Pedro Rueda por su generosidad al facilitarme éste y los datos en referencia a la circulación de este libro, desde España hacia los virreinatos americanos, durante los siglos XVI y XVII.

37 Ibid., 1184, San Andrés, f. 22.

${ }^{38}$ El dato aparece consignado en nota al pie en Mariana Labarca, "Los libros de medicina...", 356.

${ }^{39}$ La cita es para hacer evidente que desde tiempos muy remotos se ha utilizado la pomada mercurial: "Posteriormente Rogerio de Parma en 1250, Varynano de Génova en 1300, Thedorico en 1350 y Juan de Vigo, cirujano del papa Julio II, en 1514, aplicaron este medicamento contra las afecciones cutáneas, muy particularmente, si por naturaleza eran contagiosas", Luis Carreño, Algunas consideraciones acerca de la Pomada Mercurial doble (Puebla: Imprenta de la viuda de I. Boclar, 1894), 9.

${ }^{40}$ Rumbo Prieto et al., "Revisión histórica...", 41.
} 
periencia del médico agustino. En la valorización de esta última surge la segunda obra, en donde aún subyace, aunque de manera más sutil, la obra de Vigo.

\section{Tratado breve de medicina (1592)}

La publicación de este tratado conocerá tiempos más benignos, lejos de la pestilencia del "cocolistle". Sin duda este factor es determinante, pues aun dentro de las alabanzas retóricas de Farfán al virrey don Luis de Velasco (hijo), no puede dejar de señalar que con su llegada a Nueva España, esta tierra comenzó a estar más sana. ${ }^{41}$ Las partes anatómica y quirúrgica, que habían predominado en la primera obra, son ahora libros "menores" dentro de la nueva intención de Farfán. En efecto, este libro se concentra en ampliar la última parte de su libro escrito 13 años antes. La ampliación se dará en ciertos casos, principalmente en los que valoran la materia médica americana para la curación de diversas enfermedades, ${ }^{42}$ pero se reducirá en los apartados donde el pensamiento de Vigo predominaba en la prosa de Farfán:

\begin{tabular}{|c|c|c|c|}
\hline $\begin{array}{c}\text { Practica in arte chirur- } \\
\text { gica copiosa (1519). } \\
\text { Juan de Vigo }\end{array}$ & $\begin{array}{l}\text { Libro o práctica en ci- } \\
\text { rurgía (1548). Trad. de } \\
\text { Miguel Juan Pascual }\end{array}$ & $\begin{array}{c}\text { Tratado breve } \\
\text { de cirugía (1579). } \\
\text { Agustín Farfán }\end{array}$ & $\begin{array}{c}\text { Tratado breve } \\
\text { de medicina (1592). } \\
\text { Agustín Farfán }\end{array}$ \\
\hline $\begin{array}{l}\text { Cum oculi ad usuz } \\
\text { vite maxime conferant } \\
\text { e dulcedinem eius } \\
\text { magna cum diligenta } \\
\text { de eoruz natura } \\
\text { dicendum est ut } \\
\text { cognita corpum } \\
\text { dispositione morbis } \\
\text { corumdem medicus } \\
\text { possit opitulari. De situ } \\
\text { itaque eorum oibus } \\
\text { est manifestum. Sub } \\
\text { fronte ideo a natura } \\
\text { duo oculi fuerunt }\end{array}$ & $\begin{array}{l}\text { Como los ojos sean } \\
\text { para el uso de la vida: } \\
\text { y mayormente para } \\
\text { su dulçura con grande } \\
\text { diligencia de la natu- } \\
\text { ra dellos, avemos de } \\
\text { decir para que conos- } \\
\text { cida disposición dellos } \\
\text { pueda el médico } \\
\text { a sus enfermedades } \\
\text { dar remedio. El lugar } \\
\text { dellos a todos es } \\
\text { manifiesto: debaxo } \\
\text { de la frente fueron }\end{array}$ & $\begin{array}{l}\text { Para el uso de la } \\
\text { vida humana, fueron } \\
\text { hechos los ojos, } \\
\text { mayormente para } \\
\text { la dulçura de ella. Y } \\
\text { así conviene, que el } \\
\text { médico se esmere en } \\
\text { el conocimiento de las } \\
\text { enfermedades dellos, } \\
\text { para darles el remedio } \\
\text { necesario, como a } \\
\text { miembros tan puecho- } \\
\text { sos. El sitio y lugar } \\
\text { de los ojos a todos es }\end{array}$ & $\begin{array}{l}\text { Los ojos fueron para } \\
\text { el uso de la vida y } \\
\text { para la dulzura de ella. } \\
\text { Y así conviene que el } \\
\text { médico se remite en } \\
\text { el conocimiento } \\
\text { y cura de las enfer- } \\
\text { medades de ellos. Y } \\
\text { darles luego remedio } \\
\text { como a miembros tan } \\
\text { necesarios. El sitio } \\
\text { y lugar de los ojos } \\
\text { (como todos saben) } \\
\text { es debajo de la frente. }\end{array}$ \\
\hline
\end{tabular}

\footnotetext{
${ }^{41}$ Agustín Farfán, Tratado breve de medicina y de todas las enfermedades que a cada passo se ofrecen (México: Pedro Ocharte, 1592), ff. Ilv-IVr.

42 El "toloatzin", el "topotzan", el "ololiuhqui", el "cocolmécatl", la "jicamilla itztictlanoquiloni", las hojas "xiztlantectli", la "colilla de tlacuache", la "bezoar del buche de la iguana", etc., son sólo algunas pocas de las materias americanas que emplea Farfán en sus diversos tratamientos y que enriquecieron el arte de la medicina occidental. Véase Farfán, Tratado breve de medicina, ed. de Cortés Guadarrama, 321-377.
} 


\begin{tabular}{|c|c|c|c|}
\hline $\begin{array}{c}\text { Practica in arte chirur- } \\
\text { gica copiosa (1519). } \\
\text { Juan de Vigo }\end{array}$ & $\begin{array}{l}\text { Libro o práctica en ci- } \\
\text { rurgía (1548). Trad. de } \\
\text { Miguel Juan Pascual }\end{array}$ & $\begin{array}{c}\text { Tratado breve } \\
\text { de cirugía (1579). } \\
\text { Agustín Farfán }\end{array}$ & $\begin{array}{c}\text { Tratado breve } \\
\text { de medicina (1592). } \\
\text { Agustín Farfán }\end{array}$ \\
\hline $\begin{array}{l}\text { ordenati: ut totum } \\
\text { corpus a varius e } \\
\text { diversis extrinsecis } \\
\text { nocumentis tuecantur. } \\
\text { Sunt etiam tanquez } \\
\text { custodes viridarii. } \\
\text { Membra sunt insuper } \\
\text { ex septez tunicis } \\
\text { tribusquez humoribus } \\
\text { confecta. Et propterea } \\
\text { i hunc modum eorum } \\
\text { compositionem des- } \\
\text { cribam (f. VIIr). }\end{array}$ & $\begin{array}{l}\text { por natura ordenados } \\
\text { los dos ojos para que } \\
\text { defienden el cuerpo } \\
\text { de varios y diversos } \\
\text { daños extrínsecos: } \\
\text { son como guardado- } \\
\text { res de Viñas: y son } \\
\text { miembros compues- } \\
\text { tos de siete túnicas y } \\
\text { de tres humores: y por } \\
\text { esso en esta forma es- } \\
\text { cribiré la composición } \\
\text { dellos (f. IXv). }\end{array}$ & $\begin{array}{l}\text { notorio, el qual } \\
\text { es debaxo de la frente, } \\
\text { son vazios y horada- } \\
\text { dos los dos ojos por la } \\
\text { naturaleza, para que } \\
\text { defiendan al cuerpo } \\
\text { de varios y diversos } \\
\text { males, y de muchas } \\
\text { desventuras, que por } \\
\text { acá fuera acontecen. } \\
\text { Son los ojos atalayas } \\
\text { y guardas del cuerpo, } \\
\text { son miembros } \\
\text { compuestos de siete } \\
\text { túnicas, y de tres hu- } \\
\text { mores, y en esta forma } \\
\text { que se sigue, pintaré y } \\
\text { escribiré la disposición } \\
\text { de ellos (ff. } 13 v \text {-14r). }\end{array}$ & $\begin{array}{l}\text { Son los ojos vacíos y } \\
\text { horadados, son para } \\
\text { defender el cuerpo de } \\
\text { varios y diversos ma- } \\
\text { les, que a cada paso } \\
\text { acontecen. Los ojos } \\
\text { son atalayas y guardas } \\
\text { del cuerpo. Son miem- } \\
\text { bros compuestos de } \\
\text { siete túnicas y de tres } \\
\text { humores. En la forma } \\
\text { que se sigue diré la } \\
\text { disposición de ellos (ff. } \\
\text { 334v-335r). }\end{array}$ \\
\hline
\end{tabular}

Ésta será la versión que gustará y triunfará, a tal grado que la reedición de 1610 es idéntica, salvo por las variantes tipográficas. Más que una nueva traducción, pareciera que Farfán resume y condensa lo que él mismo tradujo 13 años antes, apoyándose ahora en su crecida experiencia. Esto se aprecia mejor en la sexta parte del tratado de 1579, que en la versión de 1592 formará parte de los tres primeros libros. Aquí un ejemplo del tercero:

Tratado breve de cirugía (1579). Agustín Farfán

\section{Tratado breve de medicina (1592).} Agustín Farfán
Haze el mesmo efecto y muy mejor, si el que está con calentura éthica es poderoso para tener dos amas, o chichiguas, que en lengua mexicana es lo mesmo, y mamare la leche dellas, volviendo a la primera edad. Y si en dos o tres meses con la sola leche se passare, le será muy más provechoso, y créanme que es remedio admirable (f. 264r).
Para curar esta calentura héctica he usado muchas veces de este remedio que ahora diré, y a honra y gloria de Dios han sanado siete enfermos -hombres y mujeres- de ocho o diez de los que han venido a mis manos, y el remedio es este: hago que el enfermo mame seis meses o cuatro, y los dos primeros le mando que no coma ni beba otra cosa, sino que mame (f. 279). 
Aunque esta resolución de abreviar y priorizar la experiencia sea uno de los más importantes factores del éxito editorial, hay otros elementos en juego. En primer lugar, están los que atañen exclusivamente a esta edición y responden a los intereses de la reescritura del autor agustino. Así pues, está claro que las ideas de Vigo aún siguen resonando por el libro cuarto y quinto (respectivamente, la penúltima y la última parte), con los títulos: "Cirugía breve hecha por el padre fray Agustín Farfán" y "Anatomía breve hecha por el padre fray Agustín Farfán". Por "hecha" sabemos ya que se refiere a su traducción y adaptación de las ideas de Vigo. Si todavía permanecen en este libro, se debe a una resolución práctica: el trabajo de 13 años atrás no es desechado, se aprovecha en las dos materias que deben complementar un tratado general de medicina casera: anatomía y cirugía. Mas, como se ha dicho, son ahora una incidencia menor en el tratamiento y la disposición de los temas del tratado de 1592. Principalmente los libros primero, segundo y en menor medida el tercero, con los respectivos subtítulos de "Tratado breve de medicina y de todas las enfermedades", "De muchas enfermedades e indisposiciones que a cada paso se ofrecen" y "Breve tratado de todas las calenturas y de la cura de ellas", son mucho más atractivos que en el primer libro.

La experiencia del médico agustino ha visto y probado la efectividad y facilidad con la que se consiguen los elementos curativos de la medicina indígena, tan al alcance de cualquiera en contacto y convivencia con los nativos del altiplano mexicano. Así pues, es en este libro donde el concepto de una medicina híbrida se manifiesta con singular contundencia, pues al repertorio de plantas, raíces, piedras y animales que podían conseguirse en el tianguis más próximo y a los remedios curativos de una tradición bajomedieval hipocrática-galenista arabizada se aúnan las ideas quirúrgicas y anatómicas asentadas en la Practica in arte chirurgica copiosa. Una combinación que ya estaba presente desde el tratado de 1579, pero que aquí se beneficia con un segundo filtro de valoración por parte de un autor más experimentado y dispuesto a reescribir, con base en ésta, otro tratado breve. En síntesis, las propuestas de Vigo para ver por la salud de la sociedad italiana del XVI pervivirán en Nueva España durante la primera mitad del siglo XVII a través de Farfán y, con ello, aparecerá una segunda etapa -más allá del texto- en los mencionados elementos en juego de esta singular obra, que explican también el porqué de una reedición.

En efecto, aparecen en 1610, cuando el libro es impreso por Gerónimo Balli en la Ciudad de México. En ese entonces Farfán tenía seis años de haber muerto y la orden de los agustinos aprovecha el regreso del virrey Luis de Ve- 
lasco -tras su estancia en el virreinato del Perú- para solicitar su reimpresión, ya como un texto médico perteneciente a la orden. Hecho que se comprueba desde el grabado de la portada, en donde aparece el mismísimo san Agustín, a diferencia de los tratados breves de 1579 y 1592, en donde aparecía un grabado de fray Agustín Farfán. ${ }^{43}$
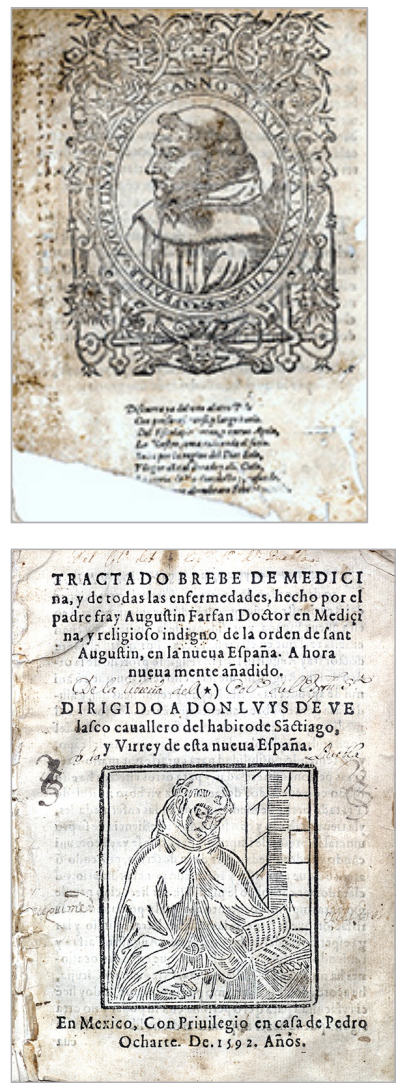

Imagen 5. Grabado de fray Agustín Farfán ubicado al final del Tratado breve de cirugía (1579). BNM.
Imagen 6. Grabado de fray Agustín Farfán en la portada del Tratado breve de medicina (1592), que perteneció a la librería del Colegio del Espíritu Santo (Puebla). BNM (copia fotostática).

\footnotetext{
${ }^{43}$ Está claro que el grabado del tratado de 1579 es el mismísimo Farfán (el único retrato de un médico novohispano de los siglos XVI y XVII hecho en vida, como señala Somolinos d'Ardois en Capítulos de Historia médica mexicana, 225. El grabado de 1592 es malo y sólo se distingue a un fraile leyendo, con un libro en la mano. Considero que es también Farfán, 13 años más viejo. Aunque, claro, uno de los atributos iconográficos de san Agustín son sus libros y objetos de estudio; no obstante, también lo son su mitra y báculo episcopal, tal y como aparece en la portada del libro de 1579. Así pues, esta cuestión sigue abierta.
} 


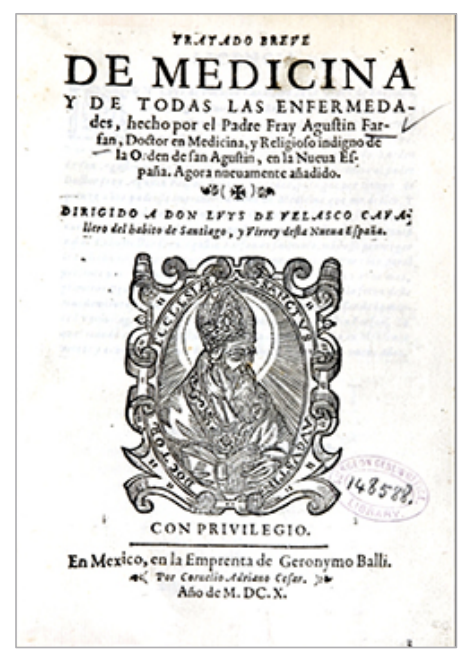

Imagen 7. Grabado de san Agustín en el Tratado breve de medicina (1610). National Library of Medicine.

Dentro de estos hechos cabe precisar que nuestro médico agustino nunca se presentó en sus tratados breves como un miembro de la tradición intelectual de su orden religiosa. En cambio, se presenta como procurador de la salud física y espiritual ${ }^{44}$ de aquellos novohispanos que, por vivir en pueblos de indios, en las minas o en otras zonas rurales apartadas, no podían acudir con un médico validado en lo institucional. En este sentido, Farfán nunca se escudó detrás de Juan de Vigo como una autoridad pertinente para los intereses exclusivos de su Orden en Nueva España, sino como autoridad pertinente para la medicina novohispana.

Sin embargo, el gran quiebre en esta posición se da en la reedición de 1610, pues los agustinos de México se hicieron de este libro de medicina con un interés exclusivo para su causa política. Al hacerlo Farfán y, de manera velada, Vigo quedaron como las auctoritates que servirán, desde el campo de la medicina, a un incipiente proyecto que se consolidará hacia la segunda mitad del siglo XVII, de mano de los "monarcas", hombres novohispanos, criollos, de gran poder social y político ante lo institucional, "que ocupaban durante dos o tres trienios el provincialato y que elegían a su antojo a los provinciales y demás

\footnotetext{
${ }^{44}$ Hecho que se comprueba en que su tratado es, sin lugar a dudas, uno de los más religiosos que se publicarán en Nueva España, al mostrar una tremenda preocupación por procurar la confesión del enfermo. Además: "Los agustinos, al nacer como la tercera orden mendicante, agregaron a su carácter eremítico y contemplativo, el nuevo cariz de vida activa que implicaba la cura de almas", Antonio Rubial García, Una monarquía criolla. (La provincia agustina en el siglo XVII) (México: Conaculta, 1990), 21.
} 
autoridades". ${ }^{45}$ Estos personajes construirán un caso sui generis dentro de las órdenes mendicantes novohispanas, llegando a crear una monarquía criolla surgida desde la provincia agustina de México. ${ }^{46}$

Así se explica la situación en la cual se encontraba el Tratado breve de medicina y la prórroga que recibe por ocho años más para que el convento "de su orden" pueda usar la "merced y privilegio" que se le dio al autor en vida. Evidentemente, éste es el único paratexto que cambia en relación a la impresión de 1592. Escribe por mandato del virrey, Luis de Velasco, Martín López de Gauna:

Por quanto fray Vicente de Mijangos, Procurador general de la orden de San Agustín, me ha fecho relación, que por mí se dio licencia al padre Doctor fray Agustín Farfán de la dicha orden, par que por tiempo de quinze años pudiesse imprimir un libro de Medicina que me dedicó. Y por aver sucedido en este derecho el Convento de la dicha su orden, y averse cumplido el dicho tiempo no se usava dél, pidiendo: que atento a que el dicho Doctor fray Agustín Farfán es fallecido, mandasse prorrogarle el dicho tiempo y privilegio por el tiempo que me pareciere. Por tanto, por el presente prorrogo el dicho tiempo y privilegio por otros ocho años más, primeros y siguientes; que corran y se cuenten desde el día de la fecha deste mandamiento, y dentro dellos pueda el dicho Convento usar la merced y privilegio que se le dio al dicho Doctor fray Agustín Farfán. Lo qual mando no impida justicia ni persona alguna. Fecho en México a veinte y ocho del mes de Março de mil y seiscientos y nueve años. ${ }^{47}$

La suerte estaba echada para este libro y, en el marco legal y civil, beneficiaría en lo económico al Convento de San Agustín en México hasta 1617, por lo menos. Fray Vicente Mijangos profesó en Oaxaca en 1585; fue definidor en 1614 y 1620; prior de México en 1617, 1619 y 1622. Fue propuesto, con Tomás de

45 Ibid. 27.

46 También conocida como Provincia del Santísimo Nombre de Jesús, que se diferencia de la de San Nicolás Tolentino, Michoacán. "El fenómeno existía en la Nueva España desde hacía mucho tiempo y los nombres de Peralta, De los Ríos, Mendoza y Delgado habían llegado a oídos del Consejo de Indias desde la década de los 30, asociados con la palabra 'corrupción' y con el problema de la alternativa. En una orden predominante criolla desde fines de la centuria anterior, los frailes peninsulares comenzaron a perder control de los puestos claves de la provincia y solicitaron a la corona y al papado que se instituyera la ocupación alternativa de los cargos principales; a partir del breve de 1627, en los siete oficios más importantes de la provincia, deberían predominar durante un trienio los nacidos en España y al siguientes los naturales de Indias", ibid., 13.

${ }^{47}$ Agustín Farfán, Tratado breve de medicina (México: Gerónimo Balli, 1610), f. Ilr. 
Aranguren y Miguel de Sosa (que finalmente sería electo), para provincial de Michoacán en el capítulo de Cuitzeo de 1620, por el visitador Martín de Aragón. ${ }^{48}$ En 1609, en su calidad de procurador general de la orden de los agustinos, cuando solicita al virrey la apropiación de la obra, habían pasado 76 años desde la llegada de la Orden de San Agustín a Nueva España. Antonio Rubial ha demostrado que numerosos jóvenes criollos -no siempre con auténtica vocación religiosa- vieron en los mendicantes la única vía para medrar en la sociedad. ${ }^{49}$ Los conventos urbanos crecieron y se vieron en la necesidad de alimentar a un creciente número de miembros. Además, los religiosos agustinos peninsulares ya no llegaban a Nueva España, sino que eran encauzados a la misión de Filipinas. Esto provocó que la orden se convirtiese en una de las primeras instituciones criollas y, con ello, plantease una serie de conflictos hasta entonces no vistos: en 1603 se dividió la congregación, los peninsulares quedaron en la Provincia de San Nicolás Tolentino, Michoacán, y los criollos en la de México.

Éste fue el caldo de cultivo que verá el arribo de los "monarcas" a finales de la década de los 20. De este caso tan sui generis es de nuestro interés ver la paradoja en la que cayó el Tratado breve de medicina de Farfán: pensado desde una intención médica para servir a españoles y criollos lejos de los centros urbanos y que necesitasen de una curación casera y práctica, desde 1610 hasta los ocho años de permiso del virrey el libro servirá para abastecer, mediante sus ganancias, a uno de los centros urbanos más importantes de Nueva España, el Convento de San Agustín en México. En este sentido, la reedición de la obra, caso único en la literatura médica, coincide con el otro tratado médico que le iguala en ediciones novohispanas, el Tesoro de medicinas $(1672,1674)$ del venerable Gregorio López: un uso político del libro en beneficio del criollismo.

\section{Conclusiones}

La brevedad es fundamental para las obras de Farfán, facilita la practicidad e intervención casera a manos del propio enfermo, con síntomas leves, o de algún familiar que se quisiese arriesgar, ante la gravedad, con alguna cura más compleja. En ambos casos, una selección de lo asentado en la Practica in arte chirurgica copiosa (1514) de Juan de Vigo está presente tanto en el Tratado breve de cirugía

\footnotetext{
${ }^{48}$ Alipio Ruiz Zavala, Historia de la Provincia Agustiniana del Santísimo Nombre de Jesús de México, t. Il (México: Porrúa, 1984), 556.

${ }^{49}$ Rubial, Una monarquía criolla.
} 
de 1579 como en el Tratado breve de medicina de 1592 y en su reedición de 1610. Con ello, una medicina de la primera mitad del XVI, destinada a la enseñanza universitaria, saldrá de las aulas y estará presente en pueblos de indios, en las minas y zonas más rurales de Nueva España, o al menos esa será su intención.

En el primer tratado escrito por Farfán es más pronunciada la influencia de Vigo; en el segundo más sutil, pero aún se deja leer. Sin lugar a dudas, gracias a estas dos obras la historia de la medicina valora la relevancia de fray Agustín Farfán para la medicina novohispana. Por supuesto, sus dos tratados breves no opacan que fue un médico respetado en la sociedad novohispana y uno de sus protagonistas. Entre otras cosas, el cabildo de la Ciudad de México lo nombró protomédico; renunció en 1568, antes de convertirse en agustino, y fue sustituido por el doctor De la Torre; en 1572 trabajó en el Hospital de Jesús al lado del doctor De la Fuente, primer médico en ostentar la cátedra de medicina en la Real Universidad de México; validó, en 1578, el libro Suma y recopilación de cirugía del cirujano romancista más importante de la Nueva España del XVI, Alonso López de Hinojosos. Sirvió 36 años a los agustinos y, en las lagunas documentales de su biografía, ya como médico, se le ve entregado a su vida religiosa o cumpliendo mandados en conventos de indios. Tras su muerte, en 1604, el rector de la Real Universidad de México convocará las honras fúnebres, so pena de descuento económico a quienes se resistieran a acudir. ${ }^{50}$

Con esta trayectoria parecería que con su sola presencia causaba autoridad, sin embargo, no todos sus colegas estuvieron dispuestos a guardarle respeto. Juan de Barrios cuenta que no hubo manera de sortear con palabras la diferencia que tuvo con fray Agustín Farfán: Ilegaron a las manos por culpa del tratamiento que recomendó el primero y que desechó el segundo para el fraile dominico Christóval de Ortega. ${ }^{51}$ ¿Acaso la furia incontenible de Barrios tenía historia y tuvo como uno de sus antecedentes lo que se ha desarrollado en estas páginas? ¿Sabía que Farfán le debía mucho a Juan de Vigo y nunca lo manifestó en sus obras? ¿Acaso otros médicos de la época sabían que al leer a Farfán leían parte de las ideas del médico del papa Julio II? De saberse, ¿otros médicos asentados en Nueva España le excusaban de este hecho, pues sus tratados nacieron con la finalidad de la difusión y el apoyo a los necesitados, y no para la enseñanza en la cátedra de medicina en la Real Universidad de México?

\footnotetext{
${ }^{50}$ Somolinos d'Ardois, Capítulos de Historia médica mexicana, 219-227. Cortés Guadarrama, "Estudio introductorio", 150-154.

51 Juan de Barrios, Verdadera medicina, cirugía y astrología, en tres libros dividida (México: Fernando Balli, 1607), f. 182v.
} 
Queden aquí estas preguntas para futuras investigaciones. Lo único en claro es que la sombra de Practica in arte chirurgica copiosa de Juan de Vigo en sus tratados breves no oscurece una trayectoria, sino que se funde con la silueta del propio fray Agustín Farfán.

\section{Referencias}

Arias de Benavides, Pedro. Secretos de chirurgia, especial de las enfermedades de Morbo gálico y Lamparones y Mirrarchia, y así mismo la manera como se curan los Indios de llagas y heridas y otras pasiones en la Indias, muy útil y provechoso para en España y otros muchos secretos de chirurgía hasta agora no escriptos. Valladolid: Francisco Fernández de Córdoba, 1567.

Barrios, Juan de. Verdadera medicina, cirugía y astrología, en tres libros dividida. México: Fernando Balli, 1607.

Berceo, Gonzalo de. Milagros de Nuestra Señora. Edición de Fernando Baños, estudio de Isabel Uría. Madrid: Crítica, 1997.

Carreño, Luis. Algunas consideraciones acerca de la Pomada Mercurial doble. Puebla: Imprenta de la viuda de I. Boclar, 1894.

Conti, Andrea A. "The Anatomical and Historical Background of Surgery: Major Surgical Achievements during the Middle Ages and the Renaissance". Italian Journal of Anatomy and Embryology, núm. 124 (2019): 212-215.

Cortés Guadarrama, Marcos. "Cefalea en mujeres novohispanas (1613-1727): invenciones fallidas de la medicina y de la hagiografía en la Vida del siervo de Dios Gregorio López". En La sombra de Thánatos: enfermedad, muerte y viudedad en los siglos XVI y XVII. Edición de Fernando J. Pancorbo y Oana Sâmbrian, de próxima aparición.

Cortés Guadarrama, Marcos. "El cuerno de unicornio en la Nueva España: conocimiento boticario y prescripción de médicos". Revista Historia de América, núm. 161 (2021): 275-306.

Cortés Guadarrama, Marcos. "Estudio introductorio". En fray Agustín Farfán, Tratado breve de medicina y de todas las enfermedades, 15-172. Madrid: Iberoamericana / Vervuert, 2020.

Cortés Guadarrama, Marcos. "Lactancia y lactantes novohispanos: prefiguración de un mal más allá del cuerpo. Un caso del eclecticismo literario en el arte médico de la Nueva España". Melisendra, núm. 2 (2020): 68-86.

Farfán, Agustín. Tratado breve de cirugía y del conocimiento y cura de algunas enfermedades que en esta tierra más comúnmente suelen haber. México: Antonio Ricardo, 1579. 
Farfán, Agustín. Tratado breve de medicina y de todas las enfermedades. Edición de Marcos Cortés Guadarrama. Madrid: Iberoamericana / Vervuert, 2020.

Farfán, Agustín. Tratado breve de medicina y de todas las enfermedades que a cada passo se ofrecen. México: Pedro Ocharte, 1592.

Farfán, Agustín. Tratado breve de medicina y de todas las enfermedades que a cada passo se ofrecen. México: Imprenta de Gerónimo Balli, 1610.

García, Esteban. Crónica de la Provincia Agustiniana del Santísimo nombre de Jesús de México, Libro quinto. Edición de Gregorio de Santiago Vela. Madrid: Imprenta G. López Hornos, 1918.

García Icazbalceta, Joaquín. Bibliografía Mexicana del siglo XVI. Edición de Agustín Millares Carlo. México: Fondo de Cultura Económica, 1981. [1a. ed. 1954].

Guevara Flores, Sandra Elena. "La construcción sociocultural del cocoliztli en la epidemia de 1545 a 1548 en la Nueva España". Tesis de doctorado. Universitat Autònoma de Barcelona, 2017. Acceso el 1o. de octubre de 2021. https://ddd.uab.cat/pub/tesis/2017/hdl_10803_457738/segf1de1.pdf.

Jarcho, Saul. "Medicine in the Sixteenth-Century. New Spain as Illustrate by the Writings of Bravo, Farfán and Vargas Machuca". Bulletin of the History of Medicine, núm. 31 (1957): 425-444.

Labarca Mariana. "Los libros de medicina en el Chile del siglo XVIII: tipologías, propietarios y dinámicas de circulación". Anuario Colombiano de Historia Social y de la Cultura 47, núm. 2 (2020): 345-371.

López de Hinojosos, Alonso. Suma y recopilación de cirugía. Con un arte para sangrar muy útily provechosa. Edición de Germán Somolinos d'Ardois, Roberto Olivera, Samuel Fastlicht y Alfredo López Austin. México: Academia Nacional de Medicina, 1977. [1a. ed. México: Antonio Ricardo, 1578].

López de Hinojosos, Alonso. Suma y recopilación de cirugía. Con un arte para sangrar y examen de barberos. Va añadido en esta el origen y nascimiento de las reumas y las enfermedades que dellas proceden, con otras cosas muy provechosas para acudir al remedio dellas, y de otras muchas enfermedades. México: Pedro Balli, 1595.

Madrigal Lomba, Ramón. El Renacimiento. Época y medicina. Xalapa: Universidad Veracruzana, 2015.

Martínez Hernández, Gerardo. "Más allá de la primera cátedra de medicina en el Nuevo Mundo: tiempo, vida y obra de Juan de la Fuente". Asclepio 72, núm. 2 (2020): 314-331. 
Monardes, Nicolás. Primera y segunda y tercera partes de la historia medicinal de las cosas que se traen de nuestras Indias Occidentales, que sirven en medicina. Sevilla: Alonso Escrivano, 1574.

Pérez Marín, Yarí. Marvels of Medicine. Literature and Scientific Enquiry in Early Colonial Spanish America. Liverpool: University Press, 2020.

Real Academia Española. Corpus Diacrónico del Español (CORDE). [En línea].

Rodríguez-Sala, María Luisa y Verónica Ramírez Ortega. Los médicos en la Nueva España y sus redes sociales. Etapa preilustrada (1730-1779). México: Universidad Nacional Autónoma de México, 2016.

Rubial García, Antonio. Una monarquía criolla. (La provincia agustina en el siglo XVII). México: Consejo Nacional para la Cultura y las Artes, 1990.

Ruiz Zavala, Alipio. Historia de la Provincia Agustiniana del Santísimo Nombre de Jesús de México. Tomo II. México: Porrúa, 1984.

Rumbo Prieto, José María, Alba Cortizas Montero y Juan Santiago Cortizas-Rey. "Revisión histórica sobre el uso en heridas del emplasto confortativo de Vigo". Enfermería Dermatológica, año 11, núm. 31 (2017): 36-42.

Somolinos d'Ardois, Germán. Capítulos de Historia médica mexicana. Relación alfabética de los profesionistas médicos, o en conexión con la medicina, que practicaron en territorio mexicano (1521-1618). Tomo III. México: Sociedad Mexicana de Historia y Filosofía de la Medicina, [1978].

Vidal Ortega, Antonino. "Los inicios de la ciencia moderna en el Caribe neogranadino: Pedro López de León, teoría y práctica en la cirugía de la Cartagena del siglo XVII". Asclepio 72, núm. 2 (2020): 316.

Vigo, loannis de. Practica in arte chirurgica copiosa. Lyon [Lugduni]: In aedibus lacobi Myt..., sumptib[us]... Vince[n]tii de Portonariis, 1519.

Vigo, Juan de. Libro o prática [sic] en cirurgía del muy famoso y experto doctor Juan de Vigo: médico que fue y cirurgiano del sanctíssimo padre Julio segundo. Traducido de lengua latina en nuestro vulgar castellano por el doctor Miguel Juan Pascual, valenciano. [S. I.: s. i.], 1548.

Vigo, Juan de. Teorica y practica en cirugia. Traducida del latín al castellano por el doctor Miguel Juan Pasqual, valenciano. Madrid: Imprenta de Ángel Pasqual Rubio, 1717.

V. AA. Traducción y transmisión doctrinal de la medicina grecolatina desde la Antigüedad hasta el Mundo Moderno. Edición de María Teresa Santamaría Hernández. Cuenca: Ediciones de la Universidad Castilla-La Mancha, 2016. Weckmann, Luis. La herencia medieval de México. 2 vols. México: El Colegio de México, 1984. 